\title{
Halloween, Organization, and the Ethics of Uncanny Celebration
}

\author{
Simon Kelly ${ }^{1}$ (D) Kathleen Riach ${ }^{2}$
}

Received: 20 July 2017 / Accepted: 8 June 2018 / Published online: 25 June 2018

(C) The Author(s) 2018

\begin{abstract}
This article examines the relationship between organizational ethics, the uncanny, and the annual celebration of Halloween. We begin by exploring the traditional and contemporary organizational function of Halloween as 'tension-management ritual' (Etzioni, Sociol Theory 18(1):44-59, 2000) through which collective fears, anxieties, and fantasies are played out and given material expression. Combining the uncanny with the folkloric concept of ostension, we then examine an incident in which UK supermarket retailers made national news headlines for selling offensive Halloween costumes depicting 'escaped mental patients'. Rather than treating this incident as a problem of moral hygiene-in which products are removed, apologies made, and lessons learned-we consider the value of Halloween as a unique and disruptive ethical encounter with the uncanny Other. Looking beyond its commercial appeal and controversy, we reflect on the creative, generous, and disruptive potential of Halloween as both tension-management ritual and unique organizational space of hospitality through which to receive and embrace alterity and so discover the homely within the unheimlich.
\end{abstract}

Keywords Alterity $\cdot$ Halloween $\cdot$ Mental health $\cdot$ Organizational ethics $\cdot$ Other $\cdot$ Uncanny

\section{Introduction}

The new spectrality is there - and we're entirely within this real illusion. We've nothing more than this real illusion before us and behind us. There's no longer an outside, neither a nostalgic one, nor a mythic one, nor any urgency for reason to disengage us from the spectrality of the real. There's neither place nor time - and this is the real. Only a radical 'Unheimlich' remains in which we're immersed.

Negri, (1999, p. 9)

In the Autumn of 2013, national supermarket chains and online retailers in the United Kingdom made news headlines

Simon Kelly

s.kelly@hud.ac.uk

Kathleen Riach

kathleen.riach@monash.edu

1 Department of Management, Huddersfield Business School, University of Huddersfield, Queensgate, Huddersfield, West Yorkshire HD1 3DH, UK

2 Department of Management, Faculty of Business and Economics, Monash University, PO Box 197, Caulfield East, VIC 3145, Australia for selling adult Halloween costumes based on the theme of the 'escaped mental patient' and 'psycho-ward' (BBC September 2013). The online catalogue items depicted male figures in blood spattered faux medical gowns and straightjackets, wielding knives, and syringes. Mental health charities, the news media, and social media campaigners responded by branding the costumes offensive and insensitive both to those living with mental health issues and to the carers, professions, and institutions that support them (Betton et al. 2015). Several weeks later, and in response to growing pressure, two supermarkets stocking the costumes issued press releases apologizing for any offence caused and the costumes were withdrawn from sale. At the same time, a second news headline covered a similar campaign calling for UK theme park company Thorpe Park to close its own mental health-themed Halloween attraction the Asylum Maze in which paying customers are chased around an indoor maze by actors dressed as violent escaped mental patients (BBC October 2013). An unsuccessful petition was launched with the theme park owners responding by citing the previous 8 years in which this attraction had run without complaint. In the weeks that followed, news media and online commentators engaged in polarizing debates around the morality of producing and consuming 'mental patient' themed Halloween products, but as October 31 st came around and the 
news agenda shifted, reports of the incident were eventually consigned to the online archive.

Drawing on the emerging field of 'organizational ethics' as distinct from business ethics (Byers and Rhodes 2007; Hancock 2008; Lim 2007; Pullen and Rhodes 2014), this article contends that this incident of 'mental health' themed Halloween products and services deserves to be revisited and re-examined-not as a problem of moral hygiene in which products are removed, apologies made, and lessons learned-but as a unique ethical encounter with the uncanny Other. Unlike other religious and civic celebrations, Halloween invites participants to come face-to-face with difference, alterity, and with it new and potentially unsettling subjectivities. This is an inherently uncanny relationship between self and other that is arguably present in many forms of everyday and organizational experience (Beyes and Steyaert 2013; Royle 2003), but one that is heightened during an engagement with Halloween (Mueller et al. 2007). In seeking to situate Halloween within the study of organization, our article begins by exploring its affective and aesthetic function as a kind of uncanny 'tension-management ritual' (Etzioni 2000), in which the structures and conventions of 'normal' organization are temporarily suspended and inverted through acts of 'ritual rebellion' and 'playing out' (Nelson 2000). If folk rituals and homemade costumes and artefacts might have once reflected the very specific fears and anxieties of local communities preparing for the change and transformation of the seasons by turning to mysticism and folklore (Feldman 2001; Santino 1994), then contemporary attempts to commercialize Halloween arguably bring with them similarly rich cultural and organizational insights. Through our analysis of the 2013 Halloween costume incident, we observe that the simple removal of 'offensive' mental health-themed products from public view appear to merely deny a more complex ethical call to scrutinize the perceived relationship between perceptions of mental health, masculine violence, and institutionalization as expressed in and through the aesthetic of the Halloween costumes and theme park experiences. Indeed, the reoccurrence of less high-profile instances of 'offensive' Halloween products in the years that followed this particular scandal (see Alexander 2014; Lennon et al. 2016; Scott 2017) suggests that the more such incidents are negated on moral grounds, the more this negation seems to create the conditions for their return. As such, the contemporary celebration Halloween itself seems to offer little in terms of seasonal tension-management and is instead a particularly potent organizational site for an unresolved cycle of commercial offense-contrition-offense.

In seeking to understand and potentially disrupt this cycle, we argue that such instances in which themes of Halloween, violence, and mental health become intertwined should not be dismissed as a moral transgression or commercial misdemeanour to be somehow repaired and overcome, but as a fragile moment of uncanny disturbance and disruption (Masschelein 2011; Pullen and Rhodes 2014) through which acts of commercial 'playing out' serve to express, but also contain and ultimately normalize fears of otherness and alterity. Drawing on the folkloric concept of ostension (see Dégh and Vázsonyi 1983; Tolbert 2013)—a process through which myth and legend is turned into a material reality-we demonstrate how such uncanny disturbances represented in the aesthetic and embodied commercial choices of the supermarket retailers can and should be read as a subtle form of ostensive action in which collective fears, anxieties, and prejudices of the unknown and unknowable Other are given affective force and material expression. The supermarket costumes in question were marketed for men, advertised using male models, and based on hyper-masculine horror movie tropes of serial killers, single-mindedly hunting down and murdering their victims usually represented as feminine or feminized Others (see Creed 1993; Vachhani 2014). As we observe, the intrusion of commercial enterprise into private and domestic seasonal celebrations of Halloween further serves to reinforce a narrow and constraining set of power relations and gender norms that seek to control and repress otherness and alterity by turning cinematic tropes of escaped mental patients into a lived experience through the manufacture and sale of themed costumes. Finally, rather than seeking to denounce or explain away such products we conclude by offering an alternative reading through which such tropes and stereotypes might be read very differently—not just as offensive symbols of mental health—but as an embodiment of what Antonio Negri calls a 'radical unheimlich' (1999)—expressed here in costume form as a grotesque and violent monstrous guardian of an uncertain and unethical moral order whose presence serves to close down an openness to alterity-as difference is reduce to same and otherness turned into abjection. In challenging and subverting this figure, we recommend a turn to an 'ethics of organization' in which generosity and responsibility to the Other are foregrounded over legislation and moral outrage (Hancock 2008; Pullen and Rhodes 2014). This requires a recognition that Halloween-as a unique form of organizing - can still offer a ritual space for exploring, experimenting with, and celebrating alterity if the ethical (rather than moral and legislative) lesson of this incident is heeded: That alterity cannot be branded, bought or sold, and that seeking to commercialize and profit from holidays and celebrations like Halloween risks continually invoking the immoral, offensive, and the grotesque. In contrast, we contend that Halloween could and should represent a unique ethical opportunity to experience and embrace tension and uncertainty by creating a generous (albeit disruptive) organizational space of hospitality in which to receive and so take responsibility for the Others that are invoked in collective attempts to make ourselves at home with the unheimlich. 


\section{Halloween as Ethical Encounter}

The starting point for our analysis of Halloween and the uncanny is based on an observation that seasonal celebrations are often not included in studies of management and organization. Although such celebrations are a global event driving and shaping the spending habits of entire nations, it is still rare for management and organizational scholars to consider them a topic worthy of serious attention (Hancock 2016; Hancock and Rehn 2011). Indeed, as Hancock reflects in his study of organizing Christmas, it is perhaps the association with childhood whimsy that means such events lack a sense of intellectual gravitas (Hancock 2016, p. 755). Of course, the same could certainly be said of the study of Halloween where in place of romantic childhood whimsy there is the more macabre and fantastical associations with death, transformation, and the monstrous (Santino 1994; Skal 1994). Yet, like Christmas, Halloween has a significant economic impact with the population of the United States in 2017 reportedly spending a record \$9.1 billion on Halloween confectionary and products (National Retail Federation 2017), and the UK spending around $£ 320$ million on the same (Dover 2017). Halloween therefore matters economically, but it is also an important cultural event that presents broader organizational, moral, and ethical challenges when producing, consuming, and observing this seasonable celebration.

As a rich blend of organized celebration and ethical encounter, Halloween is unique in that it is recognized and observed in many countries around the world and yet it is not a religious or holy day, or a civic holiday. As Etzioni (2000) following Durkheim observes, holidays of any kind serve to represent the cultural attributes and mood of a society and community, but they also serve as important public rituals for integration and recommitment through which individuals can be integrated into and later reaffirm their commitment to societal values through celebrations like birthdays, anniversaries, religious or holy days, and national memorials. However, there are other holidays that serve a different purpose in what Etzioni terms 'tension-management rituals'. These are holidays that provide a means of safely playing out collective unease by temporarily inverting or making fun of existing cultural and social norms and power structures with the goal of re-establishing such structures once this tension has been allowed expression. Examples of such rituals might include April Fool's Day in which truth telling is inverted, or Leap Years in which gendered marriage proposal customs are reversed. Yet curiously, Halloween presents a problem for Etzioni's typology in which this seasonal event is eschewed with a brief note that it might fit (albeit uncomfortably) within the 'tension-management' category. Yet for Etzioni it does not really seem to belong anywhere (see Etzioni 2000, p. 48). As we will later observe, this discomfort and lack of analytical home speaks directly to Halloween's intimate relationship with the uncanny. After all, Halloween is not really a 'day' as such, but something that occurs sometime after dark and until the passing of midnight. It may even take place on a weekend prior to or just after October 31st (Morton 2012). However, despite these discomforts and fluidities, Halloween as a celebration predates other Western religious and monotheistic dates in the seasonal calendar with its pre-Christian roots as Samhain (pronounced 'sowin') - an ancient Irish Celtic festival marking the end of the summer harvest and the beginning of winter (also bringing with it the darkest nights and shortest days (Feldman 2001; Santino 1994)). Halloween also represents what in folklore studies is termed a seasonal calendar custom (Simpson and Roud 2003). These are yearly events that, like the uncanny, may struggle to be fully defined or described, but which mark a collective transition or moment of significant change and transformation of self, community, and the world.

In its late twentieth and early twenty-first century incarnations, Halloween arguably still serves as a calendar custom, but one whose purpose is made less clear as it exists somewhere between a generic party night, a commercial exercise in satisfying the desires and habits of consumers, and as something as likely to be observed by the media and large online and high street retailers as it is by communities or individuals (Belk 1990). Here we might also observe that the aesthetic of the celebration has become something of a retrotopia (Bauman 2017) in which traditional and often non-binary Halloween figures drawn from folklore and mysticism such as fairies (or the mischievous Celtic sidh), demons, ghosts, and goblins are replaced with violent hypermasculine monsters of gothic horror and over-sexualized feminine objects of desire (Alexander 2014; Nelson 2000). As David Skal (1994) describes in his cultural analysis of horror cinema, the insertion of predatory male horror icons like Dracula, Frankenstein's Monster, The Mummy, and The Wolf Man into the Halloween pantheon has nothing to do with ancient tradition. Instead, it was a deliberate re-branding strategy by Universal Studios in 1957 to make money from their ailing horror movie stock by targeting the new U.S. home television market. As Skal observes, as television screens in homes across North America became awash with horror monsters, 'Monster Culture' was born as figures from television and cinema became synonymous with Halloween celebrations across the world as a celebration of the monstrous, the murderous, and the masculine. Similarly, the practice of dressing up in costume and 'trick or treating' in which gift giving is inverted and caught in tension between hospitality/hostility (Caputo 1997; Rehn 2014), ${ }^{1}$ may

\footnotetext{
1 The implicit hostility and risk of selecting 'trick' is evident in the decision made by UK retailer ASDA supermarket in 2004 to ban the
} 
also have the appearance of an ancient European custom, but historically is reported to have first appeared as a term used in 1920s North America, before becoming the established children's door-to-door search for sweets and candy by the 1950s (Feldman 2001; Morton 2012). Yet despite (or perhaps because of) this liquid retropotic history endlessly blending fact, fiction, and fantasy, Halloween has persisted as an adaptable calendar custom to expand and become the globally recognized event and consumer brand it is today (Alexander 2014; Belk 1990).

Yet Halloween is not a comfortable calendar custom to participate in and even in its late twentieth and early twentyfirst century incarnations it is regularly a site for controversy, danger, and offence. These might be controversies and scandals involving race and gender (see Mueller et al. 2007; Lennon et al. 2016), or the perceived threat of demonic BlackEyed Children (Lockley 2014), predatory Killer Clowns (Evans 2016), or worries over safety as seen in the public panic in the United States throughout the 1970s concerning poisoned candy and chocolates containing razor blades that persisted into the following decades. As folklorists Dégh and Vázsonyi (1983) observe, such perceived threats and panics are often based on urban myths that capture public imagination and spread. However, some also become part of actual events such as the tragic death in Texas in 1974 of 8-year-old Timothy O'Bryan who died of cyanide poisoning after eating Halloween candy. As Dégh and Vázsonyi recount, Timothy's father was found guilty and convicted for the murder of his son and was later executed in 1984-but not before his prison nick-name The Candy Man went on to create a new urban myth and Halloween monster. Such cases are an important reminder that Halloween is something more than a seasonal celebration, calendar custom, or tensionmanagement ritual. In its contemporary manifestations as a unique mode of organization, the celebration of Halloween represents an ever changing and complex ethical encounter with the uncanny Other.

\section{The Uncanny and an Ethics of Organization}

In recent years, there has been a growing critical debate concerning the notion of and limits to a business and corporate ethics (Bevan and Corvellec 2007; Jones 2003; Rasche 2010). As Lim (2007) notes, where business ethics might provide an important system of governance and set of legal limitations to manage the pursuit of profit and power, the very alignment of ethics with business goals and ends itself

\section{Footnote 1 (continued)}

sale of eggs to teenagers in the weeks leading up to Halloween (Morton 2012, 91). presents an ethical dilemma. This is particularly so when considering a Levinasian ethics through which to encounter the strangeness of the other ( $\operatorname{Lim} 2007$, p. 251) - an unknowability, that Lim argues, the utilitarianism of business cannot accommodate. Similarly, Beyers and Rhodes (2007) reflect on Levinasian themes of justice and responsibility as potentially antithetical to many formal and rulebound notions of business and corporate ethics. As they remark, the pursuit of justice in particular 'should not here serve as an excuse for distancing or blinding me from the Other, nor one of ethically absolving me from the exercise of power' (Beyers and Rhodes 2007, p. 249).

More recently, Pullen and Rhodes (2014) assert the need for an embodied or corporeal ethics in which the tenets of formal ethical rules and procedure are replaced with a privileging of practical and embodied ethics grounded in bodies and everyday conduct. Building on Hancock's (2008) adaptation of the work of Rosalyn Diprose (2002), they contend that unlike legislative notions of business ethics an ethics of organization is never a final accomplishment and is never settled. Rather it is an ongoing and deliberately radical engagement with and exploration of the disruptive potential of generosity, hospitality, and openness to the Other. As Pullen and Rhodes (2014, p. 249) observe, a radical corporeal ethics as 'pre-reflective embodied interaction is one where to be ethical is to respond to the other with generosity before thinking about one's own advantage and before imposing organizational schemes'. Where themes of strangeness, otherness, responsibility, embodiment, openness, and generosity speak to the organizational context of ethics in opposition to the corporate, we suggest that Halloween too can be read as operating at the disruptive intersection of the known/unknown, familiar/strange, embodied/disembodied, hospitality/hostility, difference/same. As such, an encounter with Halloween requires not only an ethical sensibility, but an appreciation of and respect for its Other, its disruptive double, the presence of which can quickly transform pleasant Halloween celebrations into spaces of threat, offence, and scandal. ${ }^{2}$

\footnotetext{
2 As the incidents described in this article attest, Halloween has always had a powerful disruptive potential with perhaps one the most infamous examples being Orson Welles' radio adaptation of H.G. Wells' The War of the Worlds, first broadcast on the evening of 31 October 1938. The radio play represented as a newscast of an alien invasion created such widespread panic across parts of North America that Welles had to formally apologize to the media and the public the following day. However, as Welles argued, the staging of his play on Halloween night was more than just a prank, it was a deliberate attempt to engage in an ethical form of disruption. As Welles proclaimed: 'The radio was believed in America. That was a voice from heaven, you see. And I wanted to destroy that as dramatically as possible' (Welles, in Henderson 2008).
} 
This is because more than anything else, Halloween is a celebration of the uncanny. Like the possibility of ethics, the uncanny can be difficult to describe or define with any precision or satisfaction. As recently proposed by Masschelein (2011) and later applied by Beyes and Steyaert (2013), the uncanny presents an analytical challenge as it actively resists categorization as concept. It is something experienced, something affective, but with every attempt to define or contain it resulting in a doubling and with it the creation of other possibilities. So 'uncanny' could be described in terms of its German translation from unheimlich meaning 'unhomely'. It equally can mean creepy, scary, unsettling, unfamiliar, and so on, but it can also translate as 'furtive' and 'hidden'. As Masschelein (2011, p. 11) observes, the uncanny may be more usefully considered as negative or 'unconcept':

In this sense, the term "unconcept" exceeds the unconscious dynamics of repression and the return of the repressed [...] It also serves as a reminder of the concept's peculiar location "in between" or "on the verge": on the verge of sliding from the plane of immanence onto the plane of composition and vice versa, on the verge of between concept and affect, and on the verge of no longer being a concept, of dissipating again into chaos or into doxa and emerging from it in unexpected ways.

This unending movement between concept and affect is why all things uncanny should not be reduced merely to the frightening, spooky, or horrifying. To experience something as uncanny can sometimes include the frightening, but this is to miss the more profound character of uncanniness in that it is our very familiarity with that which we now fear that provides it with its own unique quality as a source of disquiet and terror (Royle 2003). In Sigmund Freud's 1919 essay The Uncanny, he spends an entire section exploring the origins of the word itself in order to underline the importance of the 'home' and the 'familiar' as foundations for this peculiar form of experience. Indeed, it is Freud's short essay that provides most intellectual starting points for any investigation of uncanniness. For Freud, this is a sensation intimately bound up with (masculine) fears of castration, one that he explores through a close reading of ETA Hoffman's The Sandman. For Freud, this text and the work of Hoffman generally is an ideal way in which to explore and understand the uncanny. Hoffman's tale of a young man's journey into madness provides many of the characteristics of Freudian uncanniness: the childhood story of the mysterious Sandman who plucks out the eyes of children to feed to his young; the doubling effect of the characters Coppola and Coppelius who may or may not be the same man (and indeed may be the Sandman himself); the doll Olympia with whom Nathanial falls in love and the eventual unravelling of his world as he is plagued by his repressed childhood terrors.

Yet just like the uncanny as unconcept, Freud's essay (and indeed Freud's own interest in this topic) is similarly haunted by its own double or doppelgänger. This is an author and text to which Freud is indebted and yet one which he (and subsequently most who read the uncanny through Freud) dismiss as a mere background or preparatory reading (see Morlock 1995; Jentsch/Sellars 1906/1995). This doppelgänger is the earlier 1906 essay by German psychologist Ernst Jentsch entitled 'On the psychology of the uncanny'. Not only does Jentsch's essay pre-date Freud's by 13 years, but his essay also provides the foundations and key characteristics and resources upon which Freud depended for his own formulation and discussion. Importantly for our interest in Halloween and ethics, Jentsch also starts from a subtly different position to Freud. Where Freud sees the uncanny as a product of psycho-sexual repression, Jentsch acknowledges that the uncanny can be both an individual and collective affective experience, an experience that he characterizes as 'psychological uncertainty'. Where Freud considers the etymology and inner psychic explanations for our experience of the uncanny, Jentsch is very careful to avoid essentialisms. As Jentsch states explicitly at the beginning of the essay, the uncanny-like Masschelein's unconcept-has no essence, no internal properties, and so cannot be approached as an independent experience or 'thing' in itself. As Jentsch cautions, we should not seek to approach the essence of the uncanny '.. . but rather to investigate how the affective excitement of the uncanny arises [...] how the psychical conditions must be constituted so that the 'uncanny' sensation emerges' (Jentsch 1906 trans Sellers 1995, p. 3). Therefore, for Jentsch the uncanny is not merely the repression of some inner sexual anxieties, but something more akin to a phenomenological encounter in which the individual or collective has a fleeting moment in which (given the right circumstances) established understandings and interpretations of the world are disrupted and suspended resulting in a sense of horror or deep discomfort about what might be 'real' and possible. It is here that Jentsch focusses on our relationship with a world of persons and things (subjects and objects)—particularly that moment when something that was assumed to be object might in fact be living, or when something assumed to be alive is revealed to be an inanimate object. It is this tension between object and subject that creates a sense of unease as Jentsch reminds us of childhood fascinations with dolls, masks, magic tricks, and human medical conditions like mental illness and epileptic 
seizures through which human movement and conscious intension appears mechanical and controlled by some other non-human force or logic. ${ }^{3}$ Moreover, for both Jentsch and Freud, it is this uncertainty and fear surrounding the identity of this Other combined with the possibility of insanity and subordination to a controlling force from outside of the human world, which so often creates a particularly potent uncanny — and we would add ethical —encounter held as it is within a schism of unease as an impossible space on the verge and in-between.

\section{Exploring the Uncanny Verge: The Commercialization of Halloween, Mental Health, and Horror}

We're deeply sorry one of our fancy dress costumes has upset people. This was an unacceptable error - the product was withdrawn immediately.

Asda Tweet @asda. 25th September 2013

I think one of the problems that retailers have is obviously in their inventories they have hundreds and hundreds and thousands of products and with that volume it is inevitable that you are - on one occasion at leastgoing to make a mistake.

Neil Saunders, Retail Analyst, Conlumino

(BBC News, 26th September 2013)

In the United Kingdom, the mainstream media tend to steer away from Halloween as a news story. Where it is mentioned it usually takes the form of a humorous '... and finally' piece on the regional television news, a local radio phone-in topic, a 'theme week' on a celebrity talent show, or as a cautionary newspaper story warning parents about the risks of allowing children to roam the streets after dark unaccompanied, or of eating too many sweets and neglecting their teeth (Tanner 2017). In short, the celebration of Halloween usually is not news in and of itself. This changed in September 2013 when two large UK supermarket chains were found to be selling Halloween costumes based on the theme of the 'escaped mental patient' (BBC News, September 2013). The costumes sold on the websites of Tesco and Asda supermarkets were aimed at an adult audience and labelled 'Mental Patient Fancy Dress Costume' (Asda) and 'Psycho Ward-Adult Costume' (Tesco) and included photographs of male models posing in fully made-up versions of what each costume might look like when worn. The first

\footnotetext{
3 Indeed, it is Jentsch's essay on the uncanny (rather than Freud's) and his notion of 'psychological uncertainty' that informs contemporary discussions of the 'uncanny valley' and its application in 3D computer animation, augmented reality, robotics, and artificial intelligence (see Tinwell 2014)
}

image of Asda's 'mental patient' shows a figure in a wig of straggled dark hair, a mask depicting a bloody and disfigured face, and wearing what appears to be a cross between a straightjacket and a white medical gown. The outfit is also blood spattered and tattered at its edges. The figure stands with his arms crossed holding a bloodied meat cleaver. The second costume provided by Tesco purports to depict a patient from a 'psycho ward'. The model is photographed as he steps menacingly towards the camera wearing a U.S. prison-style orange coverall (complete with 'Psycho Ward' label and a mock serial number emblazoned on his chest) and brandishing a large medical syringe. Instead of a ghoulish wig, this male model is bald save for a brown plastic mask that covers his nose and mouth. This is the mask made famous by Hannibal Lecter in the Hollywood movie The Silence of the Lambs which references the need to protect people from the character's cannibalistic tendencies. Accompanying (even juxtaposing) this frightening imagery is the more mundane matter of size and colour options as well as the price of each item.

The appearance of these costumes on online stores of two of the UK's most popular supermarket chains (and available online via Amazon $U K$ ) prompted an immediate public reaction. The national media, mental health charities, and campaigners all branded the costumes offensive and as demonstrating a high degree of ignorance and disregard for those living with mental illness and for the healthcare sector that supports them. Members of the public having read the news story engaged in a social media campaign on Facebook and Twitter in which self-portrait photographs (or selfies) where taken by people living with mental health issues to provide a counter image of what a mental health patient looks like using the hashtag \#mentalpatient (Betton et al. 2015). Retailers responded swiftly, and the costumes were removed from their online stores. Representatives from the companies concerned provided public apologies and donations were made to mental health charities to underscore their regret at any offence caused.

The event was recast as an 'error' or 'mistake' by the companies themselves and by news media pundits, and that seemed to be the end of the story: a poor purchasing judgement made by some supermarkets and online retailers that was quickly addressed in the face of public outrage. However, in the days and weeks following this incident a second related media event occurred. National tabloid newspapers The Sun and The Daily Mirror both broke the story that in the UK over a ten-year period around 1200 people are recorded as being killed by 'mental patients' (Bagot 2013; Parry and Moyes 2013). The story covered the tragic murder of a 16-year-old girl by a man diagnosed with paranoid schizophrenia who had only recently been released from jail. The newspapers also cited findings from a research study carried out by Manchester University, UK that suggested 
that the ten-year recorded rise of killings and patient suicides was linked to severe cuts in healthcare budgets and the subsequent strain placed on mental healthcare services.

There was no explicit mention of or link made to the earlier Halloween costume scandal, yet the two apparently unconnected news stories appeared within days of each other and all in the lead up to Halloween. Both stories also used the same provocative and medically inaccurate language of the 'mental patient' and it was not long before other national newspapers criticized The Sun and The Daily Mirror for what they described as irresponsible and misleading journalism. As the Independent Newspaper reported (Morse 2013), those living with mental illness are far more likely to be the victims rather than the perpetrators of violent crime. Moreover, the statistics used in the Manchester University research study showed an overall drop in the number of cases rather than a rise. Other voices from mental health charities such as Mind also expressed their concern at the inaccurate reporting of the study and the continued misleading connection made between mental health and violence (Mind 2013).

Another link in this pre-Halloween chain of news stories came several weeks later when UK-based theme park provider Thorpe Park was criticized by the news media and by mental health campaigners for also offering an inappropriate Halloween-themed experience based around a mental health issue (BBC News October 2013). The Thorpe Park Fright Nights are an annual Halloween event organized by the park for the past decade and include an experience called The Asylum Maze in which paying customers are chased around a maze of corridors by actors dressed as escaped and violent asylum patients-again wearing coveralls, pseudo-medical outfits, masks, and wielding knives and other weapons. As the BBC reported, the story was drawn to the attention of the national media by mental health nursing student Katie Sutton who had been told about the theme park attraction as part of a university class discussion on representations of mental health. In response, Katie launched an online petition which at the time collected over 900 signatures demanding the closure of The Asylum Maze due to its stigmatization of mental illness. Representatives at Thorpe Park refused to act on the petition citing an insufficient number of signatures. The park also defended its decision to continue with the Halloween experience by citing the previous eight years in which the event had run without drawing complaint. Since this news story first broke, the petition collected nearly 6000 signatures and the decision of Thorpe Park was questioned by others in the news media and healthcare sector who called for a change to the name of the event in future years and an end to the stereotyping of mental health issues.

A final contributing voice to this incident of Halloween, violence, and mental health also came from online fancy dress provider Escapade who in their company blog provided their own response to the unfolding mental patient news story. In this anonymous blog entry, the writer defended Escapade's decision to continue selling the controversial 'Psycho Ward' costume by arguing that the costume had nothing to do with mental health issues as it is based on existing characters from horror cinema. As they explain:

Our 'psycho killer film' products are merely an extension of that films' own merchandising - its intention is not to promote the actions of its characters or the public reaction to them, but simply the piece of art itself. We offer a chance to dress up as a character, the choice of comment you make as the wearer is entirely your own. (Escapade 2013)

This response and the subsequent decision to continue to sell 'psycho'-themed fancy dress costumes has since generated its own news interest-particularly around the company's 2017 'psychotic nympho' costume that combined violence, mental health, and female sexualization in what the president of the Royal College of Psychiatrists described as 'one of the worst I've seen' (Al-Othman 2017).

\section{Taking Ostensive Action}

The supermarkets who apologetically withdrew their Halloween costumes arguably engaged in a moral and legislative act (Byers and Rhodes 2007; Hancock 2008), a calculation that would provide the more expedient way of resolving this issue through apology and repentance. This was an 'unacceptable error' and something not intended. Yet as the Escapade blog post above suggests, these costumes where thought about and designed. Materials were ordered and stitched together, masks moulded, product orders placed, models and photographers employed, and advertising platforms produced and circulated. To describe these products as an 'error' seems to overlook the scale of planning, organization, and labour untaken. Additionally, an attempt to reconstruct this event as an error or mistake also replaces the possibility for ethical engagement with a crude moral certainty, a transgression that can be resolved and so overcome. Yet where making a moral decision-whether through apology, or by appealing to artistic freedom and consumer choice-may provide a sense of closure and security, it also risks missing the point. The aesthetic of the costumes, the implied existence of an asylum and associated institutional frameworks indexed through serial numbers, straight-jackets and coveralls, and the transgressions of the monstrous masculine figures as 'escapees' all draw attention to and prey upon an uncanny collective fear of otherness and the everpresent threat of disorganization and institutional failure. Arguably, this is emblematic of a wider poor perception of 
mental illness in the UK and beyond, an illness that still struggles to be recognized and respected alongside other more outwardly visible, measurable, and treatable biological conditions (Mind 2013). Indeed, one of the challenges of understanding mental health generally is that 'health' and 'illness' are treated as such definitive and opposing labels (Dale and Burrell 2014; Jack and Brewis 2005).

Therefore, rather than seeking to dismiss or resolve the existence of the supermarket costumes and theme park experience, these events could be read differently by engaging with notions of the uncanny and the uncanny Other as represented in these costumes through what folklorists term ostension. Taken from the Latin 'ostendere', meaning 'to show', ostension or ostensive action (see Dégh and Vázsonyi 1983; Tolbert 2013) marks that moment in which narrative intrudes into lived social reality, and through which legends and myth are given materiality and affective force. When treated as a similar process of 'showing' or acting out, through ostensive action we might read the commercial design, creation, and marketing of these costumes in an alternative way as a means of clumsily seeking to embody and so express and exploit a profound and deeply embedded anxiety around mental health. As both Jentsch and Freud have reminded us, such anxieties refuse to be ignored and so push their way back into our lived experience. In this case, using fragments of collective urban myths, legends, and horror tropes to unsettle, disrupt, and so force an engagement with an uncanny double made into a material reality through the figure of the 'escaped mental patient'. Here we are also reminded of Jentsch's discussion of the role of the mask and doll's face as a shared symbol and terror of a disembodied consciousness watching us from the shadows; the fear of being pursued by an unstoppable entity that appears human but has all the characteristics of a cold and calculating machine; or a mechanical or animate object that may secretly be alive, observing and waiting for an opportunity to strike. Importantly, Dégh and Vázsonyi's folkloric concept of ostensive action also provides a response to the author of the Escapade blog: that such figures taken from horror cinema are not merely an expression of an artwork that consumers can choose to engage with or ignore. When read as ostension, we can argue that the uncanny doubling effect of these figures demands scrutiny and a collective - rather than individual - ethical response in which this shared 'we' takes responsibility for the uncanny double that is created out of a commercial attempt to profit from a tension-management ritual. Whether we individually choose to purchase and wear an 'escaped mental patient' costume, or watch a horror movie, there is still the ethical call to question why such figures persist, what they signify and to whom, and (perhaps more importantly) who and what they seek to constrain, contain, marginalize, and silence.

\section{Welcoming the Uncanny Other}

The fancy dress costumes, the media reporting of the dangers posed by 'mental patients', and the asylum theme park, all draw on a similar fear of violence from someone (or some thing) that appears human but is driven by an almost mechanical force. This tension between human-machine, subject/object is captured in the repeated use of the coverall and mask in the pictures promoting these products and services. These uncanny entities are excessively violent and monstrous (Thanem 2006, 2011), but they are also anonymous, hidden, furtive, and unemotional disciplined subjects. Moreover, they are institutionalized, confined, numbered, categorized, but have broken free and are now unknown, uncontrollable, and transgressive. Importantly, (and in contrast to many of the photographs shared as part of the \#mentalpatient social media campaign) they are also depictions of men and the masculine. Similarly, the choice of the names given to the costumes, the pseudo-medical clothing, syringes, and serial numbers all explicitly feed on a concern about the status, care, and security of those in society who live with mental health issues - a mysterious world which many have little direct knowledge of beyond the stories presented in news media, film, and television (McLean and Hoskin 1998; Seivers 1999). However, as a form of 'acting out' or ostensive action, the costumes also reference the far more insidious cultural and gendered representations of mental illness commonly found in popular horror movies that directly link mental ill-health with supernatural violence. Take John Carpenter's 1978 movie Halloween and the archetypal unstoppable killer Michael Myers who, like our supermarket models and theme park actors, is also dressed in a mask and coverall, wielding a large knife following his escape from a mental healthcare institution.

Organization as institutionalization is also a central theme of other such cinematic representations. Take for example Hitchcock's Psycho where the theft from an employer leads the female protagonist into similar themes of insanity, costumes, complex identities, disembodied (and multiple) voices and apparently meaningless killing. To this list we might also add movies such as The Shining, Black Christmas, The Hills Have Eyes, The Texas Chainsaw Massacre, Nightmare on Elm Street, Friday the 13th, The Exorcist, Child's Play, Candy Man, The Silence of the Lambs, Scream, and Asylum. These examples all draw connections between the medical, the institutional, the psychological, abnormality, and the threat of supernatural violence. It is also particularly worth noting that they are all almost without exception depictions of men preying upon women. In other words, there is an excessive and violent masculinity in all of the commercial and media-related representations of the escaped mental patient discussed thus far. Whether 
this is represented in the design of costumes, or characters in a theme park experience, on film or television, in each case the male killer's identity and motivations are hidden and mysterious. The on-screen personas referenced by the fancy dress costumes are cold and calculating in their actions and their apparent 'madness' does not stem from a form of hysteria, or excess of emotion as they do not lose control. On the contrary, they are purposeful, careful, efficient, almost mirroring an idealized organizational subject (consider here the extended scene in Hitchcock's Psycho in which Norman Bates meticulously cleans the bathroom following his brutal act of murder, or Hannibal Lecter's satisfaction in carefully preparing a meal made up of human body parts). This is in contrast to the other Other typically pursued by this uncanny murderous figure, the feminine screen victim who is depicted as emotionally excessive, unprepared, out of control, terrified, vulnerable, and often clumsy in their attempts to escape from danger.

Therefore, within each of these cinematic depictions and representations there is arguably a hidden other in these supermarket images whose absent-presence is signified by the very specific (and repeated) aesthetic used in each of the examples. Where Jentsch reminds us of the unsettling power that exists in the tension between subject/object, here we might also return again to Freud to ask why there is a concerted effort by commercial organizations like supermarket chains and theme parks to market such products through a combination of gendered representations of mental health and tropes taken from horror cinema? Taking inspiration from Pullen and Rhodes (2014), we suggest that an ethical and corporeal (rather than moral and corporate) response might include recognizing that embodied in the material form of the escaped mental patient costume is the phallic fear of losing one's own psychical freedom and virility. Just as one cannot know what it is like to be insane without first losing one's sanity, the manufacturers and retailers of such products invite consumers (and perhaps themselves) to indulge a fascination with all that is repressed about mental health by projecting it outward through uncanny ostensive action. ${ }^{4}$ However, we are told that responsibility for this uncanny Other does not lie with the commercial providers of such products, but with the consumer. Yet as Alexander (2014) notes in her analysis of designs of heroic male Halloween costumes, there is a denial of responsibility here on the part of manufacturers in their attempt to colonize and brand Halloween and masculinity, and in so doing to marginalize femininity and with it the possibility of difference. As Alexander argues, this is not 'a mere masquerade,

\footnotetext{
${ }^{4}$ As film director Stanley Kubrick famously stated (paraphrasing Freud), '...the uncanny is the only feeling which is more powerfully experienced in art than in life' (Ciment 1982).
}

an impersonation; rather commercially produced costumes masquerade as consumer "choice" while simultaneously masking the continued transformation of [American] masculinity into specific brand products' (2014, p. 180). In the same way, perhaps the true offence committed by these costumes is not in their aesthetic, but in the attempt to brand and so control and marginalize difference and otherness. The figure of the 'escaped mental patient' could therefore be alternatively read not as uncanny Other, but as the other reduced to same. This is a commercially sanctioned pseudoOther whose existence negates the need for any meaningful dialogue about mental health, alterity, or collective responsibility to others, as we are instead encouraged to dismiss such products simply as fun horror characters to experiment with, or as offensive and regrettable purchasing decisions later to be apologetically removed from view.

In her book The Monstrous Feminine Barbara Creed (1993) suggests that the reproduction of certain gendered aesthetics may play a significant role in how one might read events like this case of Halloween, mental health, and violence described here. As Creed observes, the use of the male 'slasher' figure in popular culture and horror cinema can (and perhaps should) be read as an attempt to express a masculine fear of castration rather than a show of strength or domination. Where for Freud it is the female who is symbolically castrated by her lack of phallic power, for Creed it is masculine fear of being castrated by the female Other that drives this horror cliché. It is the feminine, therefore, that is Other, monstrous and powerful, and so must be combated by these hyper-masculine and unemotional characters who stand for the status quo, defending sameness in the face of difference (Creed 1993; Vachhani 2014). Perhaps it is here in Creed's reclaiming of popular culture and horror that we may find a final clue as to why the supermarket costumes passed undetected through the quality checks, policies, and procedures of retailers and regulators. Was this an error or mistake, or following Creed, could it be read as a collective form of commercial ostensive action through which the costumes were produced and marketed for their implicit totemic power to somehow guard against a depletion of male power or to protect the wearer against phallocentric anxieties of the feminine Other? As Morton (2012) observes in her history of Halloween, traditional Celtic celebrations of Samhain would often draw on themes of nature, goddess worship, shapeshifting, and sexual transgression that existed at the intersection between the ordinary and the extraordinary. An example of this can be found in popular tales of the sidh (fairies) who would use the night of Samhain to cross between their world and ours to seduce, mislead, and trap unsuspecting men for all eternity in their mystical realm. Given this rich mythical context, is it perhaps unsurprising then that contemporary commercialized Halloween products are similarly shot through with tensions and contradictions 
around gender, identity, power, transgression, hospitality/ hostility, magic, and commerce. The ethical warning to be heeded may therefore be in realizing that seeking to resolve or negate such incidents by reducing them to 'mistakes', or simply erasing the evidence, not only erases any possibility of recognizing and welcoming the Other, but also makes it far more likely that such incidents will occur again in the future as unresolved anxieties seek to find expression through ostensive action and validation in new hegemonic regimes. As this article has demonstrated, this is particularly so during unsettling (and increasingly commercialized) seasonal celebrations like Halloween.

\section{Conclusion, or How to Feel at Home with the Unheimlich}

Samhain isn't evil spirits. It isn't goblins, ghosts or witches. It's the unconscious mind. We're all afraid of the dark inside ourselves.

Dr Samuel Loomis

(Halloween II, Universal Pictures)

With its uncanny themes of life and death, the supernatural, transgression, alterity, abjection, masking, and doubling, we have argued that the celebration of Halloween represents both a unique mode of organization and a complex ethical encounter. To observe this seasonable event requires one to engage with, embody, and 'play out' a blend of historical tradition, folklore and mysticism, corporate politics, popular culture, and fantasy fiction. It seems fitting at this point then to engage in our own form of ostensive action by asking the reader to heed the advice of the fictional Dr Samuel Loomis from the Halloween movie series, that participating in Halloween (or its more ancient Celtic cousin Samhain) is not to entertain or fear some external supernatural force, but instead to encounter a darkness from within. Therefore, in revisiting the incident of the 'offensive' mental patient Halloween costumes, we have sought to explore the aesthetic and affective force of Halloween as an uncanny ethical encounter with self/other, same/different, rather than as a form of supernatural and moral transgression. As we have argued, it is the conflation of morals and ethics that prevents a more nuanced understanding and appreciation of our continued relationship with the uncanny as a part of organizational life. Halloween in particular is also a reminder that commercialized expressions of our inner most fears might have something to teach us about ourselves and world we participate in and co-produce-but only if we are prepared to engage with rather than seek to negate that which comes to visit us during such rituals. Where Halloween once served as an annual catharsis for ancient fears of the unknown, or as an unsettling late-modern tension-management ritual
(Etzioni 2000), perhaps in the twenty-first century it now serves as a further expression of Negri's radical Unheimlich (Negri 1999). A magical sidh world of a different kind. A hyper-masculinized and meticulous neoliberal economic order in which we are all immersed and through which we are required to engage with complex assemblages of cultural and sexualized norms and stereotypes on a daily basis-stereotypes that we have been taught to love, fear, and consume via an exploitation of the Other.

Through our consideration of this case of Halloween fancy dress and mental health, we have recommended an alternative engagement with the commercialisation of horror and violence. Just as Barbara Creed seeks to reclaim the power of the feminine in the slasher movie, the case of the morally offensive Halloween costumes represents a similar ethical call to engage with and take responsibility for the other Others that are created as the uncanny double against whom such costumes are designed to guard against. These Others represent forms of alterity and impossibility that challenge notions of sameness, normality, the healthy, the ordinary and the accepted, but who are marginalized here by a commercial celebration and justification of the grotesque. Therefore, rather than treating the 'escaped mental patient' Halloween costume incident as an unfortunate isolated event, we have instead sought to demonstrate the value of recognizing and welcoming the uncanny Other that the celebration of Halloween could and should embody. By being open to the possibility of the Other it then possible to address more nuanced themes and questions overlooked in the initial reporting of the scandal in the news media such as why these particular costumes were made in the first place, where the references and symbolism they draw on come from and why they persist in popular culture. As uncomfortable (unheimlich) as it might be to posit such themes, particularly as they relate to the everyday lives of mental health patients, healthcare workers, retailers, social and news media outlets, such themes and questions are essential in challenging and potentially reconciling a complex ethical relationship between the organization of normality and a continued collective fascination with difference-expressed here in terms of the macabre, the mysterious, and the monstrous.

Here we might also seek to resolve Etzioni's (2000) struggle in locating Halloween within a typology of public ritual. For Halloween is a kind of tension-management ritual, but it is one that is inherently uncanny and whose purpose is ironically to resist categorization. Just as there is never any finality or accomplishment of a pursuit of ethics in organizations (Pullen and Rhodes 2014, p. 793), Halloween is similarly a seasonal ethical reminder that there is never any final relief from the tension that marks the boundaries between same and difference, natural and supernatural, the ordinary and monstrous, familiar and strange. Instead, by setting aside the commercial desire to colonize and so tame 
Halloween, we might be encouraged to learn to live with tension and uncertainty by creating a generous (albeit disruptive) uncanny space of hospitality in which to receive, understand, and so take responsibility for the others that are invoked and expressed through collective fears and anxieties. Finally, if as Negri argues we are fated to live with and so reside within the 'real illusion' of a radical Unheimlich then perhaps the starting point for any contemporary study or celebration of Halloween as organizational event should begin by acknowledging the lessons taught to us by our favourite ghost stories and horror movies: that all things 'uncanny' have a habit of returning when you least expect them. From here the uncertain greeting 'Happy Halloween' could be read as an ethical call not to fear, negate, or seek to profit from this return, but instead to invite it in by making ourselves at home with the unheimlich and in so doing to learn to enjoy the disruptive organizational potential of the familiar made strange, the homely made hostile.

\section{Compliance with Ethical Standards}

Conflict of interest All authors declare that they have no conflict of interest.

Ethical Approval This article does not contain any studies with human participants or animals performed by any of the authors.

Open Access This article is distributed under the terms of the Creative Commons Attribution 4.0 International License (http://creativeco mmons.org/licenses/by/4.0/), which permits unrestricted use, distribution, and reproduction in any medium, provided you give appropriate credit to the original author(s) and the source, provide a link to the Creative Commons license, and indicate if changes were made.

\section{References}

Alexander, S. M. (2014). The corporate masquerade: Branding masculinity through Halloween costumes. The Journal of Men's Studies, 22(3), 180-193.

Al-Othman, H. (2017). Mental health professionals say this "Psychotic Nympho" halloween costume is one of the worst they've ever seen. Buzzfeed News, 12th October 2017. Retrieved January 28, 2018 from https://www.buzzfeed.com/hannahalothman/thiscompany-has-been-criticised-for-continuing-to-sell?utm_term $=$. xmMywd6JBq\#.ttgNK6GezX.

Bagot, M. (2013). 'More than 1,200 people killed by high-risk mental health patients over past 10 years'. The Daily Mirror Newspaper (Online Edition) 7th October 2013. Retrieved June 9, 2014, from http://www.mirror.co.uk/news/uk-news/more-1200-people-kille d-high-risk-2345953.

Bauman, Z. (2017). Retrotopia. Cambridge: Polity.

BBC News Online (September 2013). Asda and Tesco withdraw Halloween patient outfits. Retrieved July 17, 2017, from http://www. bbc.co.uk/news/uk-24278768.

BBC News Online (October 2013). Thorpe Park defends Halloween asylum attraction:. Retrieved July 17, 2017, from http://www.bbc. co.uk/news/uk-england-surrey-24612748.
Belk, R. W. (1990). Halloween: An evolving American consumption ritual. Advances in Consumer Research, 17(1), 508-517.

Betton, V., Borschmann, R., Docherty, M., Coleman, S., Brown, M., \& Henderson, C. (2015). The role of social media in reducing stigma and discrimination. British Journal of Psychiatry, 206, 443-444.

Bevan, D., \& Corvellec, H. (2007). The impossibility of corporate ethics: for a Levinasian approach to managerial ethics. Business Ethics: A European Review, 16(3), 208-219.

Beyes, T., \& Steyaert, C. (2013). Strangely familiar: The uncanny and unsiting organizational analysis. Organization Studies, 34(10), $1445-1465$.

Byers, D., \& Rhodes, C. (2007). Ethics, alterity, and organizational justice. Business Ethics: A European Review, 16(3), 239-250.

Caputo, J. D. (1997). Deconstruction in a Nutshell: A Conversation with Jacques Derrida. New York: Fordham University Press.

Ciment, M. (1982). Kubrick on the shining: An interview with Michel Ciment. Retrieved June 9, 2014, from http://www.visual-memor y.co.uk/amk/doc/interview.ts.html.

Creed, B. (1993). The Monstrous Feminine: Film, feminism, psychoanalysis. London: Routledge.

Dale, K., \& Burrell, G. (2014). Being occupied: An embodied re-reading of organizational 'wellness'. Organization, 21(2), 159-177.

Dégh, L., \& Vázsonyi, A. (1983). Does the Word "Dog” Bite? Ostensive Action: A means of legend-telling. Journal of Folklore Research, 20(1), 5-34.

Diprose, R. (2002) Corporeal generosity: On giving with Nietzsche, Merleau-Ponty and Levinas. Albany, NY: State University of New York.

Dover, S. (2017) Halloween spending in the UK set to reach $£ 320$ million. Mintel, 16th October 2017. Retrieved January 30, 2018, from http://www.mintel.com/blog/retail-market-news/halloween-spend ing-in-the-uk-set-to-reach-320-million.

Escapade Fancy Dress and Party (2013). 'Mental Patient' Asda \& Tesco fancy dress outrage. Online blog, 26th September 2013. Retrieved September 26, 2013, from http://blog.escapade.co.uk/ news/mental-patient-asda-tesco-fancy-dress-outrage.asp.

Etzioni, A. (2000). Toward a theory of public ritual. Sociological Theory, 18(1), 44-59.

Evans, M. (2016). Police warn of zero-tolerance approach to 'killer clowns' ahead of Halloween. The Telegraph (online edition) 28th October 2016: http://www.telegraph.co.uk/ news/2016/10/28/police-warn-of-zero-tolerance-approach-tokiller-clowns-ahead-of/. Date Accessed: 30th October 2016.

Feldman, E. (2001). Halloween. American Heritage (Online), 52(7). Retrieved January 28, 2018, from https://www.americanheritag e.com/content/halloween.

Freud, S. (1961/1919). The Uncanny. In James Stachey (Ed.), The Standard Edition of the Complete Psychological Works of Sigmund Freud. London: The Hogarth Press.

Hancock, P. (2008). Embodied generosity and an ethics of organization. Organization Studies, 29(10), 1357-1373.

Hancock, P. (2016). A Christmas carol: A reflection on organization, society and the socio-economics of the festive season. Academy of Management Review, 41(4), 755-765.

Hancock, P., \& Rehn, A. (2011). Organizing Christmas. Organization, 18(6), 737-745.

Henderson, A. (2008). Orson Welles and the 70th Anniversary of War of the Worlds. Smithsonian National Portrait Gallery. Retrieved July 13, 2017 from http://npg.si.edu/blog/orson-welle s-and-70th-anniversary-war-worlds.

Jack, G., \& Brewis, J. (2005). Introduction to Wellness. Culture and Organization, 11(2), 65-68.

Jentsch, E. (1906/1995). On the psychology of the uncanny. Trans. R. Sellars. Angelaki: Journal of the Theoretical Humanities, 2(1), 7-16. 
Jones, C. (2003). As if business ethics were possible. 'Within such limits'... Organization, 10(2), 223-248.

Lennon, S. J., Zheng, Z., \& Fatnassi, A. (2016). Women's revealing Halloween costumes: other-objectification and sexualization. Fashion and Textiles, 3(1), 21.

Lim, M. (2007). The ethics of alterity and the teaching of otherness. Business Ethics: A European Review, 16(3), 251-263.

Lockley, M. (2014). Chilling sightings of 'Black Eyed Child' ghost spark paranormal hunt. The Mirror Newspaper (online), 28th September 2014. Retrieved January 28, 2018, from https:// www.mirror.co.uk/news/weird-news/chilling-sightings-black -eyed-child-4341525.

Masschelein, A. (2011). The unconcept: The Freudian uncanny in late-twentieth-century theory. Albany: SUNY Press.

McLean, C., \& Hoskin, K. (1998). Organizing madness: Reflections on the forms of the form. Organization, 5(4), 519-541.

Mind.org.uk (7th October 2013). Comment on The Sun's 'mental patient' front page'. Retrieved June 9, 2014, from http://www. mind.org.uk/news-campaigns/news/comment-on-the-sunsmental-patient-front-page/.

Morlock, F. (1995). Doubly uncanny: An introduction to 'on the psychology of the uncanny'. Angelaki: Journal of the Theoretical Humanities, 2(1), 17-21.

Morse, F. (2013). The Sun newspaper's '1,200 killed by mental patients' headline labelled 'irresponsible and wrong'. The Independent Newspaper (Online Edition), 7th October 2013. Retrieved June 9, 2014, from http://www.independent.co.uk/ news/uk/the-sun-newspapers-1200-killed-by-mental-patientsheadline-labelled-irresponsible-and-wrong-8863893.html.

Morton, L. (2012). Trick or Treat: A History of Halloween. London: Reaktion Books.

Mueller, J. C., Dirks, D., \& Picca, L. H. (2007). Unmasking racism: Halloween costuming and engagement of the racial other. Qualitative Sociology, 30(3), 315-335.

National Retail Federation (2017). Halloween Headquarters Survey: Halloween spending to reach record $\$ 9.1$ billion. Retrieved January 30,2018 , from https://nrf.com/resources/consumer-researchand-data/holiday-spending/halloween-headquarters.

Negri, A. (1999). The specter's smile. In M. Sprinker (Ed.) Ghostly Demarcations: A symposium on Jacques Derrida's Specters of Marx (pp. 5-16). London: Verso.

Nelson, A. (2000). Halloween costumes and gender markers. Psychology of Women Quarterly, 24(2), 137-144.

Parry, R., \& Moyes, S. (2013). 1,200 killed by mental patients: Shock 10 -year toll exposes health crisis. The Sun Newspaper (Online
Edition), 6th October 2013. Retrieved June 9, 2017, from https:// www.thesun.co.uk/archives/news/1052064/1200-killed-by-menta 1-patients/.

Pullen, A., \& Rhodes, C. (2014). Corporeal ethics and the politics of resistance in organizations. Organization, 21(6), 782-796.

Rasche, A. (2010). The limits of corporate responsibility standards. Business Ethics: A European Review, 19(3), 280-291.

Rehn, A. (2014). Gifts, gifting and gift economies: on challenging capitalism with blood, plunder and necklaces. In M. Parker, G. Cheney, V. Fournier \& C. Land (Eds.), The Routledge companion to alternative organization (pp. 198-209). New York: Routledge.

Royle, N. (2003). The Uncanny. Manchester: Manchester University Press.

Santino, J. (1994). Halloween Other Festivals: Death And Life. Tennessee: University of Tennessee Press.

Scott, E. (2017). A 'psychotic zombie nympho' Halloween costume is being criticised for stigmatising mental illness. Metro Newspaper (Online Edition), 17th October 2017. Retrieved January 28, 2018, from http://metro.co.uk/2017/10/17/a-psychotic-zombie-nymph o-halloween-costume-is-being-criticised-for-stigmatising-menta 1-illness-7005623/.

Seivers, B. (1999). Psychotic organization as a metaphoric frame for the socioanalysis of organizational and interorganizational dynamics. Administration and Society, 31(5), 588-615.

Simpson, J., \& Roud, S. (2003). Dictionary of English Folklore. Oxford: Oxford University Press.

Skal, D. (1994). The monster show: A cultural history of horror. London: Plexus.

Tanner, C. (2017). Dentist reveals the healthiest Halloween sweet treat for children and the teeth-rotting ones to avoid. Daily Mail (Online), 19th October 2017. Retrieved January 28, 2018, from http://www.dailymail.co.uk/health/article-4996632/Healthiest -sweet-treat-children-Halloween.html.

Thanem, T. (2006). Living on the edge: towards a monstrous organization theory. Organization, 13(2), 163-193.

Thanem, T. (2011). The Monstrous Organization. Cheltenham: Edward Elgar.

Tinwell, A. (2014). The Uncanny Valley in Games and Animation. Boca Raton: CRC Press.

Tolbert, J. A. (2013). "The sort of story that has you covering your mirrors": The case of Slender Man. Semiotic Review, 2.

Vachhani, S. J. (2014). Always different? Exploring the monstrousfeminine and maternal embodiment in organisation. Equality, Diversity and Inclusion: An International Journal, 33(7), 648-681. 